\title{
Incidence of childhood leukaemia and non-Hodgkin's lymphoma in the vicinity of nuclear sites in Scotland, 1968-93
}

\author{
L Sharp, R J Black, E F Harkness, P A McKinney
}

\begin{abstract}
Objectives-The primary aims were to investigate the incidence of leukaemia and non-Hodgkin's lymphoma in children resident near seven nuclear sites in Scotland and to determine whether there was any evidence of a gradient in risk with distance of residence from a nuclear site. A secondary aim was to assess the power of statistical tests for increased risk of disease near a point source when applied in the context of census data for Scotland.
\end{abstract} Methods-The study data set comprised 1287 cases of leukaemia and nonHodgkin's lymphoma diagnosed in children aged under 15 years in the period 1968-93, validated for accuracy and completeness. A study zone around each nuclear site was constructed from enumeration districts within $25 \mathrm{~km}$. Expected numbers were calculated, adjusting for sex, age, and indices of deprivation and urban-rural residence. Six statistical tests were evaluated. Stone's maximum likelihood ratio (unconditional application) was applied as the main test for general increased incidence across a study zone. The linear risk score based on enumeration districts (conditional application) was used as a secondary test for declining risk with distance from each site.

Results-More cases were observed (O) than expected (E) in the study zones around Rosyth naval base (O/E 1.02), Chapelcross electricity generating station (O/E 1.08), and Dounreay reprocessing plant (O/E 1.99). The maximum likelihood ratio test reached significance only for Dounreay $(P=0.030)$. The linear risk score test did not indicate a trend in risk with distance from any of the seven sites, including Dounreay.

Conclusions-There was no evidence of a generally increased risk of childhood leukaemia and non-Hodgkin's lymphoma around nuclear sites in Scotland, nor any evidence of a trend of decreasing risk with distance from any of the sites. There was a significant excess risk in the zone around Dounreay, which was only partially accounted for by the sociodemographic characteristics of the area. The statistical power of tests for localised increased risk of disease around a point source should be assessed in each new setting in which they are applied.

(Occup Environ Med 1996;53:823-831)
Keywords : leukaemia; childhood; nuclear sites

In 1986, Heasman and colleagues ${ }^{1}$ reported a higher than expected incidence of leukaemia in children and young adults near the Dounreay nuclear reprocessing plant in Caithness, Scotland. This led to a detailed investigation by the Committee on Medical Aspects of Radiation in the Environment (COMARE). ${ }^{2}$ The committee's original intention had been to study all nuclear sites in Scotland but, because of public and professional concern about the findings of high incidence of leukaemia in young people near both Dounreay and Sellafield, ${ }^{3}$ the only two nuclear reprocessing facilities in the United Kingdom, it was decided to concentrate on further investigation of the population living near Dounreay. A case-control study, which examined several risk factors for leukaemia, and a cohort study which compared incidence of leukaemia and other cancers in children born locally with children who attended school in the area but were born elsewhere, were carried out. ${ }^{45}$ The local incidence of leukaemia and non-Hodgkin's lymphoma have recently been re-evaluated. ${ }^{6}$ There continue to be more cases observed than expected in children and young people living in the vicinity of Dounreay, but no specific local factor which could explain the excess has been identified.

Cancer incidence and mortality in the areas near nuclear sites other than Dounreay and Sellafield in the United Kingdom have been investigated. ${ }^{7-12} \mathrm{~A}$ study of nuclear installations in England and Wales found a 15\% increase in mortality from leukaemia in those under 25 years of age in districts near to nuclear sites. ${ }^{9}$ This contrasts with the up to 10-fold excesses in incidence reported in the areas around Sellafield and Dounreay. ${ }^{13}$ The only previous study of nuclear sites in Scotland provided site specific rather than aggregated results. ${ }^{7}$ As well as a significant excess of cases in the vicinity of Dounreay, this study reported excesses within $12.5 \mathrm{~km}$ of Hunterston nuclear power generating station in 1974-84, within $12.5 \mathrm{~km}$ of Chapelcross electricity generating plant in 1979-84, and within $6.25 \mathrm{~km}$ of Rosyth nuclear submarine refitting dockyard in 1974-8, although only the Rosyth result was significant. This study, along with others from the same period, was criticised for the use of fixed geographical and temporal boundaries which might enhance or obscure locally high incidence. ${ }^{1415}$ Since then, methodological developments have resulted in a class of statistical tests which may be applied to areas 


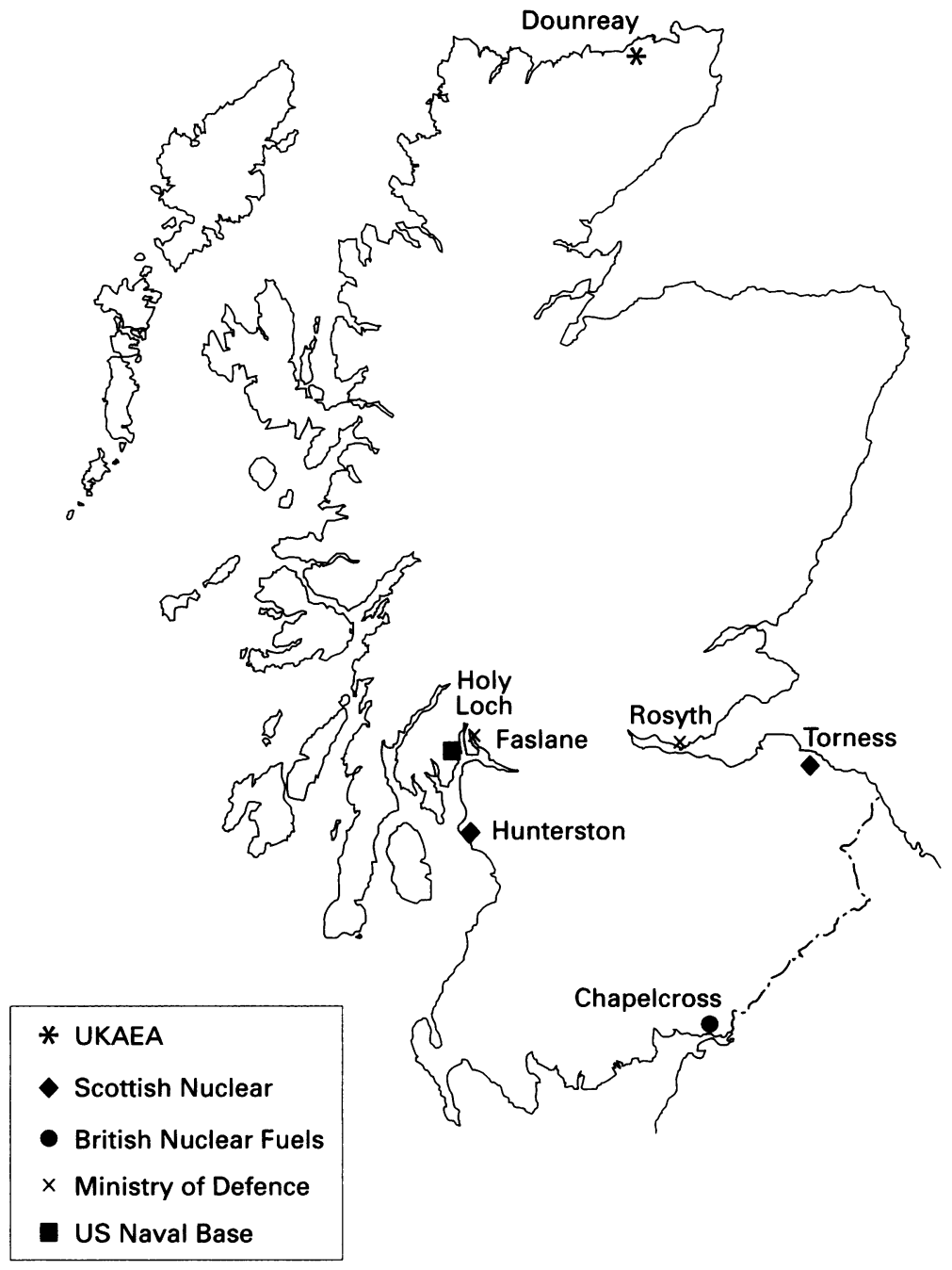

Figure 1 Nuclear sites in Scotland.
Table 1 Number of populated enumeration districts in study zone ( $<25 \mathrm{~km}$ radius from site) and population under 15 years old averaged over 1968-93, by nuclear site

\begin{tabular}{lcc}
\hline Nuclear site & $\begin{array}{l}\text { Enumeration } \\
\text { districts } \\
(n)\end{array}$ & $\begin{array}{l}\text { Average population } \\
\text { under 15 years old } \\
(n)\end{array}$ \\
\hline Dounreay & 54 & 3527 \\
Chapelcross & 187 & 10908 \\
Hunterston & 659 & 43236 \\
Torness & 155 & 7894 \\
Faslane & 648 & 45250 \\
Holy Loch & 719 & 47594 \\
Rosyth & 3064 & 197015 \\
\hline
\end{tabular}

For each site, a study zone was constructed from the 1981 enumeration districts with a population centroid within $25 \mathrm{~km}$. This radius accords with previous studies of Dounreay ${ }^{267}$ and nuclear sites in England and Wales. ${ }^{12}$ Table 1 shows the number of enumeration districts and the average population under 15 years old resident within each study zone during the period 1968-93. The population densities around the nuclear sites vary greatly with a more than 55-fold difference in the childhood population in the least compared with the most populous zones. Faslane and Holy Loch are $11 \mathrm{~km}$ apart and the results of statistical tests based on $25 \mathrm{~km}$ study zones around these sites will not be independent. The study zones around these sites and Rosyth include large parts of the Clydeside and Edinburgh conurbations, respectively. Torness and Dounreay are located in very sparsely populated areas. Chapelcross is situated close to the border with England, and this study only considers the part of the $25 \mathrm{~km}$ zone which lies in Scotland.

Each nuclear site was examined separately. Due to the heterogeneous nature of the activities of the seven sites, no pooled analyses have been conducted.

around point sources to assess risk in relat to distance from the source. ${ }^{16-18}$ This paper reports the results of the application of these techniques to the analysis of the incidence of leukaemia and non-Hodgkin's lymphoma near all nuclear sites in Scotland for the full period for which reliable childhood cancer registration data are available-namely, 1968 to 1993.

\section{Data and methods}

SITES ANALYSED AND DEFINITION OF STUDY ZONES

Figure 1 shows the locations of the seven nuclear sites in Scotland, all of which were included in the study. The only nuclear reprocessing plant, Dounreay, became operational in 1959. Three sites generate electricity. Of these, Chapelcross became operational in 1959, Hunterston A operated from 1965 to 1980 , and Hunterston B from 1976. Torness started operations in 1989 and has been included in the study for completeness. Nuclear submarines have been berthed and overhauled at Rosyth and Faslane naval installations. Rosyth has refitted nuclear submarines since 1968 and Faslane was commissioned for this work in 1967. The United States nuclear submarine base at the Holy Loch operated until 1993.

\section{DATASET OF LEUKAEMIA AND NON-HODGKIN'S} LYMPHOMA

To maintain comparability with earlier studies the analysis was based on leukaemia (ICD-9 204-208) and non-Hodgkin's lymphoma (ICD-9 200+202) combined. Registrations in children aged under 15 years at diagnosis during the period 1968-93 were derived initially from the database of the Central Scottish Cancer Registry. Childhood cancer data in Scotland have been subject to rigorous quality assurance measures to ensure completeness of ascertainment and accuracy of case details. Glass and colleagues validated leukaemia cases for $1968-81^{19}$ and, as a preliminary to the current study, a special validation exercise of all childhood cancers diagnosed in 1975-90 was conducted. Registry records were compared with those of other independently collected datasets to identify "missed" registrations, which, if confirmed, were added to the study dataset. Attempts were made to verify demographic details (particularly postcode of residence at diagnosis) and diagnostic information for all cases from additional sources including medical records and panel pathological review. A full report of the procedures and outcome of 
this exercise will be published elsewhere. Childhood cancer cases diagnosed in 1991-3 are included in the Scottish case control study of childhood leukaemia and cancer ${ }^{20}$ and routinely validated. The final dataset comprised 1287 cases. Analyses were conducted for the 0-14 age group.

POPULATION ESTIMATES AND CALCULATION OF EXPECTED NUMBERS

The smallest geographical units in Scotland for which age and sex specific population counts are available are enumeration districts for the censuses of 1971 and 1981 and output areas for 1991. The 1991 counts were adjusted for the underenumeration of the 1991 census $(-1.4 \%$ for those aged under 15$)$ such that the adjusted local government district totals conformed to the population esti-

Figure 2 Relative risk by distance from point source, simulation models $A, B$, $C$, and $D$. mates calculated from vital statistics and migration data of the Registrar General for Scotland. ${ }^{21}$ Enumeration districts for 1971 and 1991 output areas were matched to 1981 enumeration districts to obtain three point population estimates. For each enumeration district annual age and sex specific population estimates for the study period were calculated by linear interpolation between the point estimates of the enumeration districts for 1971, 1981 , and 1991.

Indicators of socioeconomic status were abstracted from the 1981 small area census statistics and a deprivation score was calculated for each enumeration district by the method of Carstairs and Morris. ${ }^{22}$ Five deprivation categories were created, each containing a fifth of the total population. For each unit postcode in Scotland an indicator of the
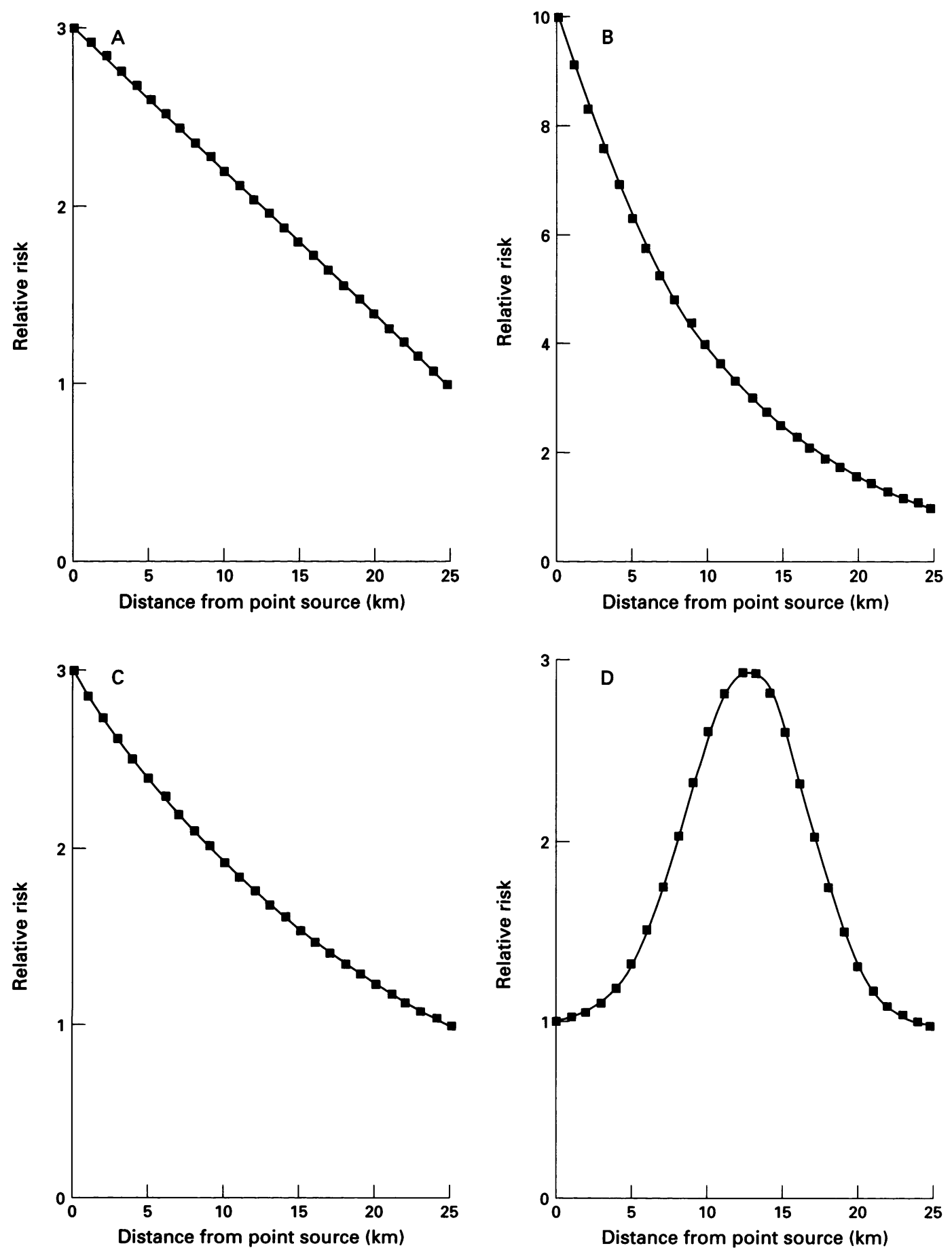
degree of urbanisation of the area is available. For each 1981 enumeration district, an urbanrural residence score in the range 1-5 was computed as a weighted average of the urbanrural indicators of the postcode units within the enumeration district. Age, sex, deprivation, and urban-rural specific rates of leukaemia and non-Hodgkin's lymphoma were calculated for Scotland as a whole and applied to each 1981 enumeration district to obtain expected numbers of cases.

\section{EVALUATION OF TEST STATISTICS}

Various test statistics for the analysis of incidence of disease near point sources of putative environmental risk have been proposed. ${ }^{16-18} 23$ These have different statistical properties and may be sensitive to particular patterns of localised risk around point sources. ${ }^{1218}$ Each of the tests can be applied in either an unconditional or conditional form. Unconditional tests are sensitive to a combination of the spatial pattern of the observed cases and any excess risk in the overall study region around the point source. By correcting for the level of risk locally, conditional tests consider only the spatial pattern of the observed cases within the study region. The tests were developed on the basis of the census geography of England and Wales, with census wards and tracts as the units of analysis. These do not have a direct equivalent in Scotland, where analyses have been based on enumeration districts, which are much smaller than census wards, or postcode sectors, which tend to be larger but are heterogeneous in terms of population size and geography.

It is unclear which of the statistical tests would be most appropriate in a particular set of circumstances. ${ }^{24}$ Therefore, we conducted an evaluation of the performance of six tests when applied to data at the level of Scottish enumeration districts. The tests assessed were Stone's maximum likelihood ratio test, ${ }^{16}$ two linear risk score tests based on rank and distance, ${ }^{12} 18$ the Poisson maximum test, ${ }^{17}$ a variant of this based on the minimum $P$ value, ${ }^{23}$ and the ratio of observed to expected cases. Our intention was to provide a basis on which to select the "best" general test for raised risk of disease in the vicinity of a point source. We,

Table 2 Power * (\%) to reject the null hypothesis at the 5\% level of significance, for selected alternative hypotheses, by point source and statistical (unconditional) test

\begin{tabular}{|c|c|c|c|c|c|c|}
\hline \multirow{2}{*}{$\begin{array}{l}\text { Alternative } \\
\text { hypothesis }\end{array}$} & \multicolumn{6}{|c|}{ Statistical test } \\
\hline & $M L R$ & $L R S-R$ & $L R S-D$ & $P \max$ & $M i n-P$ & $\mathrm{O} / \mathrm{E}$ \\
\hline $\begin{array}{l}\text { Point source S: } † \\
\text { Model A } \\
\text { Model B } \\
\text { Model C } \\
\text { Model D }\end{array}$ & $\begin{array}{l}32 \cdot 7 \\
74 \cdot 4 \\
24 \cdot 6 \\
23 \cdot 8\end{array}$ & $\begin{array}{r}19 \cdot 9 \\
60 \cdot 8 \\
17 \cdot 6 \\
9 \cdot 2\end{array}$ & $\begin{array}{l}25 \cdot 9 \\
70 \cdot 4 \\
19 \cdot 0 \\
15 \cdot 0\end{array}$ & $\begin{array}{r}11 \cdot 8 \\
33 \cdot 8 \\
12 \cdot 6 \\
5 \cdot 2\end{array}$ & $\begin{array}{l}34 \cdot 4 \\
77 \cdot 3 \\
26 \cdot 3 \\
25 \cdot 2\end{array}$ & $\begin{array}{l}16 \cdot 7 \\
48 \cdot 5 \\
11 \cdot 8 \\
13 \cdot 2\end{array}$ \\
\hline $\begin{array}{l}\text { Point source D: } \neq \\
\text { Model A } \\
\text { Model B } \\
\text { Model C } \\
\text { Model D }\end{array}$ & $\begin{array}{r}94 \cdot 3 \\
100 \cdot 0 \\
82 \cdot 2 \\
98 \cdot 6\end{array}$ & $\begin{array}{r}33 \cdot 0 \\
95 \cdot 9 \\
28 \cdot 4 \\
8 \cdot 2\end{array}$ & $\begin{array}{r}81 \cdot 8 \\
100 \cdot 0 \\
67 \cdot 2 \\
75 \cdot 4\end{array}$ & $\begin{array}{r}22 \cdot 8 \\
60 \cdot 2 \\
22 \cdot 4 \\
7 \cdot 0\end{array}$ & $\begin{array}{r}91 \cdot 3 \\
100 \cdot 0 \\
77 \cdot 1 \\
97 \cdot 8\end{array}$ & $\begin{array}{r}88 \cdot 6 \\
100 \cdot 0 \\
72 \cdot 6 \\
97 \cdot 7\end{array}$ \\
\hline
\end{tabular}

${ }^{\star}$ Estimated from 1000 stimulations for each model of risk.

tPoint source in sparsely populated area.

Point source in densely populated area.

MLR = Stone's maximum likelihood ratio test; LRS-R = linear risk score test based on rank LRS-D = linear risk score test based on distance; $P \max =$ the Poisson maximum test; Min-P variant of Poisson maximum test based on minimum $\mathrm{P}$ value; $\mathrm{O} / \mathrm{E}=$ observed to expected ratio of cases. therefore, evaluated only unconditional applications of the tests. As the effect of the extreme variation in population density near nuclear installations in Scotland on the power and behaviour of the test statistics was of concern, we considered two point sources. These were typical of the sparsely (point source $S$ ) and more densely (point source D) populated zones around Scottish nuclear sites. A dataset of 494 cases of a disease was analysed (actually a set of childhood brain tumours in Scotland which had been validated ${ }^{25}$ and was available at the time this exercise was conducted). The null distributions of the six tests were determined from 1000 simulations of cases under the assumption of uniform relative risk (1.0) throughout the study zone for each of the point sources. From these null distributions the $5 \%$ critical values of the test statistics were estimated. Four alternative hypotheses (figures 2 A-D) were chosen to represent patterns of localised increased risk :

(A) relative risk of 3.0 at $0 \mathrm{~km}$ from the point source declining linearly to 1.0 at $25 \mathrm{~km}$;

(B) relative risk of 10.0 at $0 \mathrm{~km}$ declining exponentially to 1.0 at $25 \mathrm{~km}$;

(C) relative risk of 3.0 at $0 \mathrm{~km}$ declining exponentially to 1.0 at $25 \mathrm{~km}$; and

(D) relative risk of 1.0 at $0 \mathrm{~km}$, rising to 3.0 at $12.5 \mathrm{~km}$, and returning to 1.0 at $25 \mathrm{~km}$.

Simulations of each pattern of risk were achieved by applying appropriate mathematical functions to the expected numbers of cases in each enumeration district under the null hypothesis. The number of cases arising in each simulation was unconditional on the number observed. For each point source, model of risk, and statistical test, 1000 simulations were carried out. The power of the tests to reject the null hypothesis at the $5 \%$ level of significance was estimated from the proportions of the simulations under the alternatives which exceeded the critical values.

Table 2 shows summary results from the evaluation. For all six tests the power, under each alternative hypothesis, was substantially greater when applied to the point source located in the more densely populated zone (point source D) than when applied to the point source situated in the sparsely populated area (S). Stone's maximum likelihood ratio test was the most powerful test for a general excess risk in the study area when applied to Scottish data at the level of the enumeration districts.

CHOICE OF STATISTICAL TESTS FOR ANALYSIS OF LEUKAEMIA AND NON-HODGKIN'S LYMPHOMA AROUND SCOTTISH NUCLEAR SITES Our primary aim was to determine whether there was evidence of a general excess of risk of childhood leukaemia and non-Hodgkin's lymphoma in the study zone around each nuclear site. Based on the results of the evaluation exercise, we applied the unconditional maximum likelihood ratio test. We then decided to carry out a secondary analysis to investigate the spatial pattern of the cases around each nuclear site. We applied the linear risk score test based on ranks of the enu- 
Table 3 Power* (\%) of tests to reject the null hypothesis at 5\% and $1 \%$ levels of significance, for selected alternative hypotheses, Dounreay and Hunterston, leukaemia and non-Hodgkin's lymphoma, 0-14 years, 1968-93

\begin{tabular}{|c|c|c|c|c|}
\hline \multirow{2}{*}{$\begin{array}{l}\text { Tests and } \\
\text { alternative } \\
\text { hypothesis }\end{array}$} & \multicolumn{2}{|l|}{ Dounreay } & \multicolumn{2}{|c|}{ Hunterston } \\
\hline & $\alpha=0.05$ & $\alpha=0.01$ & $\alpha=0.05$ & $\alpha=0.01$ \\
\hline $\begin{array}{l}\text { Stone's maximum likelihood } \\
\text { ratio test (unconditional): } \\
\text { Model A } \\
\text { Model B } \\
\text { Model C }\end{array}$ & $\begin{array}{l}54 \cdot 9 \\
94 \cdot 2 \\
38 \cdot 8\end{array}$ & $\begin{array}{l}32 \cdot 6 \\
84 \cdot 9 \\
19 \cdot 4\end{array}$ & $\begin{array}{l}99.9 \\
100 \cdot 0 \\
96.5\end{array}$ & $\begin{array}{l}99 \cdot 1 \\
100 \cdot 0 \\
86 \cdot 0\end{array}$ \\
\hline $\begin{array}{l}\text { Linear risk score (conditional): } \\
\text { Model A } \\
\text { Model B } \\
\text { Model C }\end{array}$ & $\begin{array}{l}9 \cdot 0 \\
25 \cdot 5 \\
9 \cdot 8\end{array}$ & $\begin{array}{l}2 \cdot 7 \\
10 \cdot 5 \\
1.9\end{array}$ & $\begin{array}{l}12 \cdot 4 \\
30 \cdot 7 \\
11 \cdot 6\end{array}$ & $\begin{array}{l}3 \cdot 2 \\
12 \cdot 6 \\
3 \cdot 5\end{array}$ \\
\hline
\end{tabular}

^Estimated from 1000 simulations for each model of risk.

meration districts, in the conditional form, to assess whether risk within each study zone decreased with distance from the point source, irrespective of whether or not there was an overall excess in the study zone.

For each nuclear site, the significance (one tailed) of the observed values of the unconditional maximum likelihood ratio and conditional linear risk score were estimated from 10000 simulations of cases of leukaemia and non-Hodgkin's lymphoma sampled from the appropriate Poisson and multinomial distributions. For descriptive purposes, observed to expected ratios were calculated, with exact $95 \%$ confidence intervals ( $95 \%$ CIs) based on the Poisson distribution. ${ }^{26}$

ASSESSMENT OF THE POWER OF THE MAXIMUM LIKELIHOOD RATIO AND LINEAR RISK SCORE TESTS IN THE ANALYSIS OF LEUKAEMIA AND NON-HODGKIN'S LYMPHOMA AROUND SCOTTISH NUCLEAR SITES

To aid in the interpretation of the results of the analysis we assessed the power of the unconditional maximum likelihood ratio test and conditional linear risk score when applied to the dataset of leukaemia and non-hodgkin's lymphoma. Dounreay and Hunterston were selected to represent nuclear facilities in sparsely and more densely populated areas. As in the evaluation study, the null distributions and critical values of the two tests were determined from simulations of the null hypothesis. The three patterns of monotonic decreasing risk with distance (models $\mathrm{A}-\mathrm{C}$ ) were simulated. The power of the unconditional maximum likelihood ratio and conditional linear risk score tests was estimated from the proportions of these simulations that exceeded the appropriate critical values for Dounreay and Hunterston.

\section{Results}

POWER OF THE MAXIMUM LIKELIHOOD RATIO AND LINEAR RISK SCORE TESTS IN THE ANALYSIS OF LEUKAEMIA AND NON-HODGKIN'S LYMPHOMA AROUND SCOTTISH NUCLEAR SITES Table 3 shows the estimated statistical power of the unconditional maximum likelihood ratio test to detect patterns of excess risk when applied to the study zones around Hunterston and Dounreay. For Hunterston, the test has high power to detect all three risk patterns. When applied to Dounreay, the power ranges from $39 \%$ (model C) to $94 \%$ (model D). Table 3 also shows the power estimates for the conditional linear risk score test. For both nuclear sites, the power to detect any of the trends of diminishing risk with distance was low.

RESULTS OF THE ANALYSIS OF LEUKAEMIA AND NON-HODGKIN'S LYMPHOMA AROUND SCOTTISH NUCLEAR SITES

Table 4 shows the total observed and expected numbers of cases of leukaemia and nonHodgkin's lymphoma, the $\mathrm{O} / \mathrm{E}$ ratios with $95 \%$ CIs, and the levels of significance of the unconditional maximum likelihood ratio and conditional linear risk score tests for the seven Scottish nuclear sites.

\section{Nuclear reprocessing plant: Dounreay}

Nine cases were observed in the study zone compared with 4.53 expected (O/E 1.99). The unconditional maximum likelihood ratio test for a general excess of risk in the $25 \mathrm{~km}$ study zone around the site yielded a significant result $(P=0.030)$. The result of the conditional linear risk score test for a trend of diminishing risk with distance from the site was not significant $(P=0.356)$.

Figure 3A shows the distribution of the population aged under 15, averaged over 1968-93, with distance from the Dounreay plant. Most of the population is concentrated within 11 to $14 \mathrm{~km}$ from the site. The cumulative observed and expected numbers of cases with distance are depicted in figure 3B. The cumulative observed number of cases exceeds that expected from a distance of $6 \mathrm{~km}$ from the site to the perimeter of the study zone.

Table 4 Observed (O) and expected ${ }^{*}(E)$ numbers of cases, observed to expected ratios (O/E), with $95 \% C I$ and $P$ values of MLR (unconditional) test + and LRS (conditional) test $\neq$, by nuclear site, leukaemia, and non-Hodgkin's lymphoma, 0-14 years, $1968-93$

\begin{tabular}{|c|c|c|c|c|c|}
\hline Nuclear site & $\begin{array}{l}\text { Observed cases } \\
\text { (O) }\end{array}$ & $\begin{array}{l}\text { Expected cases } \\
(E)\end{array}$ & $O / E$ 95\% CI & $\begin{array}{l}\text { MLR } \\
\text { P value }\end{array}$ & $\begin{array}{l}\text { LRS } \\
\text { P value }\end{array}$ \\
\hline Dounreay & 9 & 4.53 & $1.99(0.91-3.77)$ & 0.030 & $0 \cdot 356$ \\
\hline $\begin{array}{l}\text { Chapelcross } \\
\text { Hunterston } \\
\text { Torness }\end{array}$ & $\begin{array}{r}15 \\
42 \\
9\end{array}$ & $\begin{array}{r}13.90 \\
49.80 \\
9.96\end{array}$ & $\begin{array}{ll}1.08 & (0.60-1.78) \\
0.84 & (0.61-1.14) \\
0.90 & (0.41-1.72)\end{array}$ & $\begin{array}{l}0.543 \\
0.747 \\
0.820\end{array}$ & $\begin{array}{l}0.803 \\
0.591 \\
0.630\end{array}$ \\
\hline $\begin{array}{l}\text { Faslane } \\
\text { Holy Loch } \\
\text { Rosyth }\end{array}$ & $\begin{array}{r}46 \\
46 \\
232\end{array}$ & $\begin{array}{r}51 \cdot 76 \\
54 \cdot 35 \\
226 \cdot 61\end{array}$ & $\begin{array}{ll}0.89 & (0.65-1.19) \\
0.85 & (0.62-1.13) \\
1.02 & (0.90-1.16)\end{array}$ & $\begin{array}{l}0.755 \\
0.897 \\
0.244\end{array}$ & $\begin{array}{l}0 \cdot 265 \\
0 \cdot 483 \\
0 \cdot 216\end{array}$ \\
\hline
\end{tabular}

*Adjusted for age, sex, deprivation and urban or rural category.

†Estimated from 10000 simulations, with cases sampled from Poisson distribution, for each nuclear site.

†Estimated from 10000 simulations, with cases sampled from multinomial distribution, for each nuclear site. See footnote to table two for other abbreviations. 

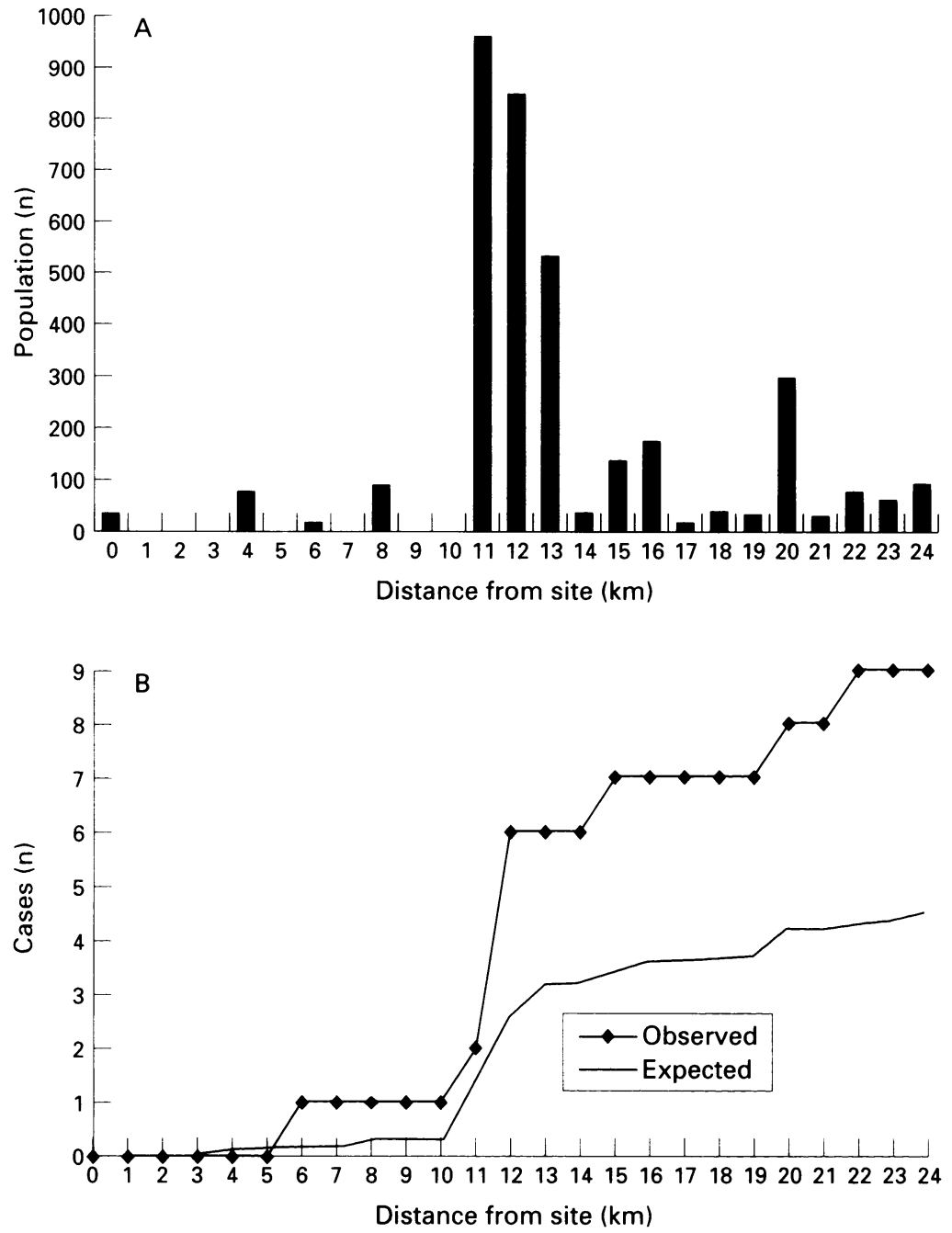

Figure 3 (A) Average population of enumeration districts within $25 \mathrm{~km}$ of Dounreay, 0-14 years, 1968-93. (B) Cumulative number of observed and expected cases by distance from Dounreay, leukaemia, and non-Hodgkin's lymphoma, 0-14 years, 1968-93.

Electricity power generating plants: Chapelcross, Hunterston, and Torness

During the study period there were 15 cases of leukaemia and non-Hodgkin's lymphoma diagnosed in the childhood population resident within $25 \mathrm{~km}$ of Chapelcross, compared with 13.90 expected $(\mathrm{O} / \mathrm{E} 1 \cdot 08)$. The maximum likelihood ratio test was not significant $(P=0.543)$. Fewer cases were observed than expected around both Hunterston and Torness resulting in $\mathrm{O} / \mathrm{E}$ ratios of 0.84 and 0.90 respectively. The linear risk score test did not indicate a pattern of decreasing risk with distance for any of these three sites.

Nuclear submarine bases: Faslane, Holy Loch, Rosyth

In the study zones around the Faslane base and the Holy Loch fewer cases were observed than expected (Faslane $\mathrm{O} / \mathrm{E}=0.89$, maximum likelihood ratio $\mathrm{P}=0.755$; Holy Loch $\mathrm{O} / \mathrm{E}$ 0.85, maximum likelihood ratio $\mathrm{P}=0.897$ ). The conditional linear risk score test did not reach significance for either Faslane $(P=0.265)$ or the Holy Loch $(P=0.483)$. A small excess of cases was observed in the area within $25 \mathrm{~km}$ of the Rosyth dockyard with 232 observed compared with 226.61 expected. The statistical test did not indicate a general excess risk in the vicinity of the site (maximum likelihood ratio $\mathrm{P}=$ $0 \cdot 244$ ) or a trend of decreasing risk with distance (linear risk score $\mathrm{P}=0 \cdot 216$ ).

\section{Discussion}

In small area analyses of rare diseases results are sensitive to variations in levels of case ascertainment. Cook-Mozaffari and colleagues found evidence of more complete ascertainment near nuclear sites than in control areas chosen for comparison. ${ }^{9}$ In the present study, we used rigorously validated cancer registration information. A validation exercise was conducted before the analysis to ensure high levels of completeness and accuracy. Data were verified from multiple sources and diagnostic review was carried out for all but a small proportion of cases. Identical procedures were used to validate all cases in Scotland, whether resident near nuclear sites or elsewhere.

Descriptive epidemiological studies of the incidence of disease in small geographical areas, with conventional methods of analysis, have been open to the criticism that the results may be dependent on a particular categorisation of the data. In this study, we used statistical tests in which the selection of the geographical boundaries is embodied in the method and controlled for in the assessment of significance. The categorisation of the data was conservative and determined before the analysis. The $25 \mathrm{~km}$ radius for the definition of the study zone was chosen to accord with previous studies. ${ }^{26712}$ Moreover, for tests designed to detect highly localised effects, it has been suggested that the overall size of the study region is not important. ${ }^{17}$ As no strong prior hypotheses regarding periods of exposure to risk factors existed, we analysed data for the entire period for which reliable information was available (1968-93). Before 1968 in Scotland only unvalidated, and unpostcoded, childhood cancer registration data and cancer mortality records are available, neither of which are appropriate for small area studies. All of the nuclear sites, with the exception of Torness, started operations before the start of the study period. Torness began generating electricity in 1989 and all of the nine cases observed were diagnosed before this date. Roman and coworkers have reported an excess of cases concentrated in children aged under 5 years resident near the atomic weapons establishments of Aldermaston and Burghfield. ${ }^{8}$ However, most United Kingdom studies of childhood cancer in the vicinity of nuclear installations have considered the complete 0-14 age group. ${ }^{26927}$ Because of this, and the few cases around some sites in Scotland, we did not conduct age specific analyses within the childhood age range $0-14$ years. A pooled analysis of all nuclear sites was considered inappropriate because of the few sites in Scotland, the heterogeneity of their operations, and the extreme variation in the population density around the sites.

Our analysis was preceded by an evaluation of the statistical power of several uncondi- 
tional tests to detect localised increased risk of disease when applied to data aggregated at the level of the enumeration districts. We simulated four patterns of increased risk associated with distance from a point source. Although it must be acknowledged that the estimated power of the tests would have differed if other risk models had been considered, those chosen were based on estimates of relative risks which have been reported near Dounreay and Sellafield. ${ }^{13}$ The most powerful test against the range of alternative hypotheses was found to be Stone's maximum likelihood ratio. The test also seemed to be sensitive to a non-monotonic pattern of increased risk (model D). This suggested that it would be the best general test of excess risk within a $25 \mathrm{~km}$ study zone, even when there is no trend of diminishing risk with distance from the point source.

The most important conclusion from our evaluation exercise was that the power of the tests is highly dependent on the population characteristics of the area under study. Although it is likely that the population density is the most influential of these characteristics, the distribution of the population, the number of units of analysis (enumeration districts in our study), and the overall expected number of cases are also likely to be important. For example, the estimates of the power of the unconditional maximum likelihood ratio test with respect to childhood leukaemia and non-Hodgkin's lymphoma around Dounreay and Hunterston (table 3) are higher than those obtained in the initial evaluation exercise (table 2). This is, in part, because the overall number of cases of leukaemia and nonHodgkin's lymphoma ( $\mathrm{n}=1287$ ) was greater than the total cases in the evaluation exercise dataset $(n=494)$ and hence, the expected number in any study zone would be larger. The effect of these factors on the power of this class of statistical tests requires further study. When considering a point source situated in a densely populated area it is likely that any one of several tests may be applied with confidence. However, if the point source is located in a sparsely populated zone the choice of test is more difficult. In studies of several point sources, the advantage, in terms of power, in choosing one particular test may be heavily outweighed by the variations in power due to differences in the populations near the point sources. Thus, it can be concluded that, although it may be possible to choose a best general test, evaluations of statistical power are required in each new setting in which a test is applied.

No evidence of a general increased incidence of childhood leukaemia and nonHodgkin's lymphoma was found near nuclear sites in Scotland. Of the sites other than Dounreay, only Chapelcross and Rosyth had more observed cases than expected after adjustment for age, sex, Carstairs' deprivation score, and urban-rural status. However, the excesses around Chapelcross and Rosyth were modest ( $8 \%$ and $2 \%$, respectively) and the results of the unconditional maximum likelihood ratio test were not significant.
Nine cases of leukaemia and non-Hodgkin's lymphoma were observed in children aged under 15 in the area within $25 \mathrm{~km}$ of Dounreay (O/E 1.99). Details of all these cases have been published previously. ${ }^{6}$ The unconditional maximum likelihood ratio test yielded a significant result $(P=0.030)$ providing evidence of an increased risk across the study zone around the site. The result of the conditional linear risk score test for a trend of decreasing risk with distance from the site, however, was not significant $(P=0.356)$. The main (maximum likelihood ratio) result arose despite estimated maximum power of $55 \%(\alpha=0.05)$ to detect a relative risk of 3.0 near the plant. Although no evidence of a trend of diminishing risk with distance from Dounreay was found, the power of the test to detect this was very low $(26 \%$ for 10 -fold increased risk at the site followed by exponential decline, $\alpha=0.05$ ). This is likely to be due to a combination of the small population units used in the test (enumeration districts), the sparse population around the site, and its uneven distribution (figure $3 \mathrm{~A}$ ). Few people live within $11 \mathrm{~km}$ of the plant and cases are most likely to arise in Thurso, the main town, situated about $12 \mathrm{~km}$ from Dounreay.

Several studies have suggested that increased incidence of childhood leukaemia is related to high social class in parents. ${ }^{28}$ This, in conjunction with conditions of rural isolation, may confer increased risk of the most common form of leukaemia, acute lymphoblastic leukaemia, in very young children through immunological isolation in infancy and subsequent late exposure to an infectious agent before the appearance of leukaemia. ${ }^{29} 30$ In common with other parts of north east Scotland, the Dounreay area is isolated and has a population of relatively high socioeconomic status. In contrast with our earlier reports, in this study attempts were made to control for socioeconomic and urban-rural status when calculating the expected number of cases in the Dounreay study zone. This resulted in an increase in the expected numbers of $14 \%$ in comparison with adjustment for age and sex only. Therefore, the excess incidence near Dounreay is partially accounted for by the sociodemographic characteristics of the area. However, after adjustment for these characteristics the excess remains significant and would not lead to a modified conclusion from this study compared with earlier studies. ${ }^{1267}$ Adjustments made with routinely collected data may not be adequate if, as suggested by Kinlen et al, ${ }^{31}$ complex local factors influencing patterns of exposure to infections are relevant in the area near Dounreay.

Our findings in relation to all nuclear sites in Scotland are consistent with other studies of multiple nuclear sites in the United Kingdom $^{9-12}$ and elsewhere. ${ }^{32-35}$ Most of these considered mortality data and used conventional methods of analysis based on standard administrative areas. None the less, despite differing study designs and including diverse nuclear facilities, the overall findings of the 
studies are not, in the main, inconsistent. Cook-Mozaffari and colleagues found no evidence of an increase in all cancer mortality in populations resident in the vicinity of nuclear sites in England and Wales compared with populations in matched control areas. ${ }^{9}$ However, a modest increase (15\%) in mortality from leukaemia in children and young adults was observed. A similarly designed study in the United States found no evidence of excess cancer mortality in areas around nuclear electricity generating plants and, specifically, no excess incidence of leukaemia in children who lived near reprocessing and weapons facilities. $^{32}$ Evidence of a slightly increased incidence of acute leukaemia in children resident close to nuclear power plants in former West Germany has been reported, with the most pronounced increased risk in children under 5 years resident within $5 \mathrm{~km}$ of sites which started operation before $1970 . .^{33}$ Most of this effect was attributed by the authors to an unexpected and unexplained low incidence in control regions. Studies of mortality from leukaemia in children and young people in France $^{34}$ and Canada ${ }^{35}$ found no evidence of increased risk associated with proximity to nuclear installations.

The only study to date to apply a similar methodology to our study is the analysis of childhood leukaemia and non-Hodgkin's lymphoma within $25 \mathrm{~km}$ of nuclear sites in England and Wales in the period 1966-87.12 Bithell and coworkers concluded that there was virtually no convincing evidence of a geographical association of childhood leukaemia and non-Hodgkin's lymphoma with nuclear installations in general, although an excess incidence persists in the area around Sellafield. Our overall conclusions for Scotland are similar. With the exception of Dounreay, there is no evidence of an increased risk of childhood leukaemia and nonHodgkin's lymphoma in the vicinity of Scottish nuclear sites. There is a significant general excess in the area within $25 \mathrm{~km}$ of the Dounreay plant. This finding shows that the original reports of increased incidence near Dounreay ${ }^{127}$ were not artefacts due to the choice of temporal and geographical boundaries. Furthermore, the excess is only partially accounted for by the sociodemographic characteristics of the area.

We thank the haematologists and pathologists throughout Scotland who collaborated in the validation study. We are grateful to The National Registry of Childhood Tumours and the MRC UK Leukaemia Trial Office, both in Oxford, for providing data for the validation study. Dr J Clarke of ISD provided hospital inpatient records. We acknowledge the assistance of the directors and staff of the five Scottish regional cancer registries and the Central Scottish Cancer Registry staff in the validation study. We are grateful to Dr J F Bithell who kindly provided programs to calculate the maximum likelihood ratio and linear risk score statistics. Staff of the Analytical Studies Group and Surveillance Group of the Scottish Cance Intelligence Unit, particularly Mr A Finlayson, assisted at various ous stages of the project and their contributions are appreciated. Professor J Little and the members of COMARE reviewers for their helpful comments.

1 Heasman MA, Urquhart JD, Kemp IW, Black RJ Childhood leukaemia in Northern Scotland [letter]. Childhood leukaemia in

2 Committee on Medical Aspects of Radiation in the Environment (COMARE). Second report. Investigation of the possible increased incidence of leukaemia in young people near the Dounreay Nuclear Establishment. Caithness, Scotland. Chairman Professor M Bobrow. London: HMSO, 1988.

3 Black D. Investigation of the possible increased incidence of cancer in West Cumbria. Report of the Independent Advisory Group. London:HMSO,1984.

4 Urquhart JD, Black RJ, Muirhead MJ, Sharp L, Maxwel $M$, Adams Jones D. Case control study of leukaemia and non-Hodgkin's lymphoma in children in Caithness nea the Dounreay nuclear installation. BMF 1991;302 687-92.

5 Black RJ, Urquhart JD, Kendrick SW, Bunch KJ, Warner J, Adams Jones D. Incidence of leukaemia and other cancers in birth and school cohorts in the Dounreay area. BMF 1992;304:1401-5.

6 Black RJ, Sharp L, Harkness EF, McKinney PA Leukaemia and non-Hodgkin's lymphoma: incidence in children and young adults resident in the Dounreay area of Caithness, Scotland in 1968-91. F Epidemiol Community Caithness, Scotland in
Health 1994;48:232-6.

7 Heasman MA, Urquhart JD, Black RJ, Kemp IW Leukaemia in young persons in Scotland: a study of its geographical distribution and relationship to nuclea installations. Health Bull (Edinb) 1987;43:147-51.

8 Roman E, Beral V, Carpenter L, Watson A, Barton C, Ryder H, Aston DL. Childhood leukaemia in the West Berkshire and Basingstoke and Northern Hampshire District Health Authority in relation to nuclear establishments in the vicinity. $B M \mathcal{F}$ 1987;294:597-602

9 Cook-Mozaffari PJ, Ashwood FL, Vincent T, Forman D, Alderson M. Cancer incidence and mortality in the vicinity of nuclear installations, England and Wales 1959-80. London: HMSO,1987. (Studies on medical and population subjects. No 51.)

10 Ewings PD, Bowie C. Leukaemia incidence in Somerset with particular reference to Hinkley Point. Somerset Health Authority, 1988

11 Committee on Medical Aspects of Radiation in the Environment (COMARE) Third Report. Report on the incidence of childhood cancer in the West Berkshire and North Hampshire area, in which are situated the Atomic Weapons Research Establishment, Aldermaston and the Royal Ordnance Factory, Burghfield. Chairman Professor M Bobrow. London: HMSO, 1989.

12 Bithell JF, Dutton SJ, Draper GJ, Neary NM. Distribution of childhood leukaemias and non-Hodgkin's lymphomas near nuclear installations in England and Wales. $B M \mathcal{F}$ 1994;309:501-5.

13 Gardner MJ. Review of reported increases of childhood cancer rates in the vicinity of nuclear installations in the UK. Fournal of the Royal Statistical Society Series $1989 ; 152: 307-25$.

14 Hills M, Alexander FE Statistical methods used in assessing the risk of disease near a source of possible environmental pollution: a review. foumal of the Royal Statistical mental pollution: a review. Foum

15 Wakeford R, Binks K, Wilkie D. Childhood leukaemia and nuclear installations. Fournal of the Royal Statistical Society Series $A$ 1989;152:61-86.

16 Stone RA. Investigation of excess environmental risks around a putative source: statistical problems and a proposed test. Stat Med 1988;7:649-60.

17 Bithell JF, Stone RA. On statistical methods for analysing the geographical distribution of cancer cases near nuclear installations. I Epidemiol Community Health 1989;43: $79-85$.

18 Bithell JF. Statistical methods for analysing point-source exposures. In: Elliott $\mathrm{P}$, et al, ed. Geographical and enviexposures. In: Elliott P, et al, ed. Geographical and environmental epidemiology: methods for smal

19 Glass S, Gray M, Eden OB, Hann IM, Gibson B. Scottish validation study of cancer registration data: childhood leukaemia 1968-81. Leuk Res 1987;2:881-5.

20 McKinney PA, Smith K, Findlay E. The Scottish case control study of childhood leukaemia and cancer: methodology and environmental measures of exposure. Health Bull 1995;53:222-9.

21 Registrar General, Scotland. Annual report. Edinburgh: HMSO, 1992

22 Carstairs V, Morris R. Deprivation and health in Scotland. Aberdeen: Aberdeen University Press, 1991.

23 Urquhart $J$. The investigation of leukaemia incidence around sites of special interest. Nuclear Energy 1991;30: 21-6.

24 Bithell J. The choice of test for detecting raised disease risk near a point source. Stat Med 1995;14:2309-22.

25 McKinney PA, Ironside JW, Harkness EF, Arango JC Doyle D, Black RJ. Registration quality and descriptive epidemiology of childhood brain tumours in Scotland, 1975-90. Br f Cancer 1994;70:973-9.

26 Breslow NE, Day NE. Statistical methods in cancer research. Vol II. The design and analysis of cohort studies. Lyon International Agency for Research on Cancer, 1987.

27 Draper GJ, Stiller CA, Cartwright RA, Craft AW, Vincent TJ. Cancer in Cumbria and in the vicinity of the Sellafield nuclear installation, 1963-90. BMF 1993;306: 89-94.

28 Draper GJ, Vincent TJ, O'Connor CM, Stiller CA. Socioeconomic factors and variations in incidence rates between country districts. In: Draper GJ, ed. The geographical epidemiology of childhood leukaemia and nongraphical epidemiology of childhood leukaemia and nonHMSO, 1991. (Studies on Medical and Population Subjects. No 53.) 
29 Alexander FE, McKinney PA, Ricketts TJ, Cartwright RA. Community lifestyle characteristics and risk of acute lymphoblastic leukaemia in children. Lancet 1990;336: phoblastic

30 Greaves MF, Alexander FE. An infectious aetiology for common acute lymphoblastic leukaemia in childhood. Leukaemia 1993;7:349-60.

31 Kinlen LJ, O'Brien F, Clark K, Balkwill A, Matthews F. Rural population mixing and childhood leukaemia: effects of the North Sea oil industry in Scotland, including the area near Dounreay nuclear site. BMF 1993;306:743-8.

32 Jablon S, Hrubec Z, Boice JD junior. Cancer in popula- tions living near nuclear facilities: a survey of mortality nationwide and incidence in two states. $¥ A M A 1991$; 265:1403-8.

33 Michaelis J, Keller B, Haaf G, Kaatsch P. Incidence of childhood malignancies in the vicinity of West German nuclear power plants. Cancer Causes Control 1992;3: 255-63.

34 Hill C, Laplanche A. Overall mortality and cancer mortality around French nuclear sites. Nature 1990;347:755-7.

35 McLaughlin JR, Clarke AE, Nishri ED, Anderson TW. Childhood leukaemia in the vicinity of Canadian nuclear facilities. Cancer Causes Control 1993;4:51-8.

\section{Correspondence and editorials}

Occupational and Environmental Medicine welcomes correspondence relating to any of the material appearing in the journal. Results from preliminary or small scale studies may also be published in the correspondence column if this seems appropriate. Letters should be not more than 500 words in length and contain a minimum of references. Tables and figures should be kept to an absolute minimum. Letters are accepted on the understanding that they may be subject to editorial revision and shortening.

The journal also publishes editorials which are normally specially commissioned. The Editor welcomes suggestions regarding suitable topics; those wishing to submit an editorial, however, should do so only after discussion with the Editor. 